\title{
Studying the Fluxes of the Marine Ecosystem Components from the Northwestern Shelf to the Deep Part of the Black Sea
}

\author{
V. L. Dorofeyev, L. I. Sukhikh* \\ Marine Hydrophysical Institute of RAS, Sevastopol, Russian Federation \\ *1.sukhikh@gmail.com
}

\begin{abstract}
Purpose. The study represents analysis of the features of the Black Sea ecosystem components transfer from the northwestern shelf to the deep-sea part and its dependence on circulation in the sea upper layer.

Methods and Results. The fluxes of water mass, nutrients and bioproduction from the shelf zone to the deep part of the sea were calculated using the current fields and biogeochemical ones resulted from the reanalysis, which, in its turn, was carried out due to the Black Sea ecosystem model including assimilation of remote sensing data both in the numerical circulation model and in the biogeochemical block. Numerical modeling permitted to calculate the fluxes through three sections that bound the shelf zone (by the capes Kaliakra and Chersonesus, and along the $200 \mathrm{~m}$ isobath). Behavior of the RIM Current jet and, consequently, direction and magnitude of the flows through the boundaries of the northwestern shelf depend on the wind stress vorticity over the western part of the Black Sea. The type of circulation with the intense RIM Current jet pressed to the shelf edge, is characterized by the pattern of distribution of the inorganic nitrogen and phytoplankton surface concentration as a narrow strip of its high values along the Black Sea western and partially southern coasts. When the RIM Current jet is weak or moves from the shelf edge (that corresponds to the low values of the wind stress vorticity) the increased concentration values are located on the northwestern shelf.

Conclusions. Direction, magnitude and character of horizontal distribution of the nutrient and bioproduction fluxes are determined mainly by circulation in the sea upper layer. The magnitude of these flows is significantly affected by difference between the nutrient and bioproduction concentrations in the shelf zone and in the deep part of the Black Sea.
\end{abstract}

Keywords: marine ecosystem, Black Sea, numerical modeling, northwestern shelf, circulation of the upper layer, nutrient transfer.

Acknowledgements: the study was carried out at the support of the RSF grant No. 17-77-30001.

For citation: Dorofeyev, V.L. and Sukhikh, L.I., 2020. Studying the Fluxes of the Marine Ecosystem Components from the Northwestern Shelf to the Deep Part of the Black Sea. Physical Oceanography, [e-journal] 27(5), pp. 460-471. doi:10.22449/1573-160X-2020-5-460-471

DOI: $10.22449 / 1573-160 X-2020-5-460-471$

(C) V. L. Dorofeyev, L. I. Sukhikh, 2020

(C) Physical Oceanography, 2020

\section{Introduction}

Understanding of the marine ecosystem functioning and variability regularities provides the forecasting and tracking the scenarios hazardous to the environment. The state of the Black Sea ecosystem is largely determined by the amount of nutrients in the upper layer of the sea, supplied mainly with river flows. The contribution of such large rivers as the Danube, Dnieper, Dniester and Southern Bug, flowing into the sea in the Northwestern Shelf (NWS) area, is $\sim 65 \%$ of all river flows into the Black Sea basin. This explains the increased content of nutrients and, as a consequence, bioproduction in the waters of the shelf, which occupies only $16 \%$ of the sea area. The penetration of nutrients and bioproducts from the NWS into the deep-water part of the Black Sea basin takes 
place due to the water exchange caused by currents in the surface layer of the sea, which is confirmed by the images obtained by satellite color scanners. From satellite maps of sea surface temperature (SST), one can also observe the penetration of cold water masses formed at the NWS in winter into the deepwater part. Due to the currents in the Black Sea upper layer, nutrient-rich waters from the NWS penetrate into the deep-water part of the sea, thus increasing the content of the marine ecosystem components in this part of the basin.

The circulation of surface waters in the NWS area has been studied in a number of works both on the basis of field measurements (for example, [1]) and using numerical modeling [2, 3]. The features of the marine ecosystem behavior at the NWS of the Black Sea were studied, for example, in [4] based on measurement data, as well as on the basis of the ecosystem models [5, 6]. In [7], the results of the studies aimed at improving the understanding of fundamental exchange processes at the boundary of the shelf and the Black Sea deep-water part are presented, and a quantitative assessment of exchange processes is given. Using a tracer carried out by river runoff, the penetration of waters from the shelf into the area of the Bosphorus Strait and along the Black Sea southern coast is shown. Part of the river water penetrates into the intermediate layers at the shelf boundary in the northwestern part of the Black Sea. On the basis of satellite measurements, the mechanisms of water exchange between the NWS and the deep-water part of the basin, caused by individual synoptic eddies, were considered $[8,9]$.

The purpose of this work is to study the features of the transfer from the NWS to the deep-water part of some components of the Black Sea ecosystem (considered in the model of producers - two groups of phytoplankton and inorganic nitrogen) and their dependence on the nature of circulation in the upper sea layer.

The study is carried out using the results of the previously performed reanalysis (sets of hydrodynamic and biogeochemical fields on a regular grid), which makes it possible to quantify the exchange between the shelf and deep-water parts of the basin.

\section{Research method}

The study of the features of nutrients and bioproduction transfer from the Black Sea NWS was carried out on the basis of numerical modeling results using the Black Sea ecosystem model. The interdisciplinary model of the Black Sea ecosystem consists of a circulation model and a biogeochemical block that describes the interactions between various components of the marine ecosystem.

The fields of the Black Sea currents used in this study are the result of a reanalysis of physical parameters for a twenty-four year period (from 1992 to 2016) [10, 11]. The reanalysis is based on a z-level model based on the approximation of a system of ocean dynamics primitive equations [12]. The applied version of the model has a horizontal spatial grid step of $4.8 \mathrm{~km}$ and 35 vertical grid levels. This spatial resolution provided adequate description, in addition to large-scale, of synoptic processes in the Black Sea.

As the boundary conditions on the free sea surface for the circulation model equations, we used the parameters of atmospheric forcing obtained from the results of the ERA-Interim (ECMWF) atmospheric reanalysis [13]: surface wind, heat and fresh water fluxes, solar radiation. The fields of these parameters for the Black Sea 
region, obtained from the official ECMWF website, were then interpolated to the model grid.

The Black Sea circulation model used the assimilation of data from satellite temperature measurements (STM), level anomalies and mean annual profiles of temperature and salinity. The sea surface temperature and the data on the sea level anomaly were taken from the archive of the Black Sea Center for Marine Forecasts of MHI. Temperature and salinity mean annual profiles were prepared based on all data from hydrographic surveys and floats for the period under consideration.

The biogeochemical block of the Black Sea ecosystem model includes 15 state variables and describes biogeochemical processes in the upper $200 \mathrm{~m}$ layer of the sea. State variables include two groups of phytoplankton (diatoms and flagellates), two size groups of zooplankton (microzooplankton $(<0.2 \mathrm{~mm}$ ) and mesozooplankton $(0.2-3.0 \mathrm{~mm})$ ), the jellyfish Aurelia aurita and the ctenophore Mnemiopsis leidyi. The food web structure also includes non-photosynthesizing bacterioplankton, dissolved and suspended organic matter and the omnivorous dinoflagellate Noctiluca scintillans. In this model nitrogen is considered as the only biogenic element limiting phytoplankton growth. The nitrogen cycle includes three inorganic compounds: ammonium, nitrates and nitrites. All the listed ecosystem components have a unit of measurement in the model mmolN $\cdot \mathrm{m}^{-3}$. Dissolved oxygen and hydrogen sulfide are also included in the model as separate state variables. The spatial step and computational horizons correspond to the circulation model. The temporal evolution of ecosystem components is described by the transport - diffusion equations, which include on the right side the terms of the type of sources - sinks, describing the interaction between the components of the ecosystem:

$$
\frac{\partial F}{\partial t}+\frac{\partial(u F)}{\partial x}+\frac{\partial(v F)}{\partial y}+\frac{\partial\left(\left(w+w_{s}\right) F\right)}{\partial z}=K_{\mathrm{h}} \nabla^{2} F+\frac{\partial}{\partial z}\left(K_{\mathrm{v}} \frac{\partial F}{\partial z}\right)+R(F),
$$

where $R(F)$ describes biogeochemical interactions between state variables $F ; w_{s}$ is a sedimentation rate of diatoms and suspended organic matter (for other components it is equal to zero); $u, v, w$ are the components of the current velocity; $K_{\mathrm{h},} K_{\mathrm{v}}$ are the coefficients of horizontal and vertical turbulent diffusion, respectively. At the mouths of large rivers nutrient fluxes proportional to their concentration and river runoff intensity were set [14]. An important feature of the biological part of reanalysis is the assimilation of measurement data from satellite color scanners. These data represent two-week fields of the chlorophyll $a$ surface concentration, prepared on the basis of SeaWiFS, MODIS, and MERIS products (URL: http://blackseacolor.com/index.htm) according to an algorithm developed specifically for the Black Sea [15]. To check the quality of the reanalysis results, their validation was carried out. It showed that the obtained fields describe quite well the real thermohaline and biogeochemical structure of the sea $[10,16]$.

The assessment of exchange parameters between the NWS and the deep-water part of the Black Sea was carried out using biogeochemical fields and current fields on a regular grid, obtained as a result of the physical reanalysis described above. 
The study period was 19 years (1998-2016). The shelf area was bounded by a curve consisting of three parts: zonal sections in the area of the Cape Chersonesus and the Cape Kaliakra (from the coast to $200 \mathrm{~m}$ depth) and a curve between them along the $200 \mathrm{~m}$ isobath. Through these sections of the NWS boundary the flows of water, inorganic nitrogen and phytoplankton in the upper 50-meter layer were calculated.

\section{Results}

The amount of nutrient flux from the shelf depends directly on water exchange. We are to consider the values of water mass fluxes through the surfaces bounding the NWS area in the upper 50-meter layer (Fig. 1, a). The curves shown in the graphs represent averaged by moving average mean monthly values.

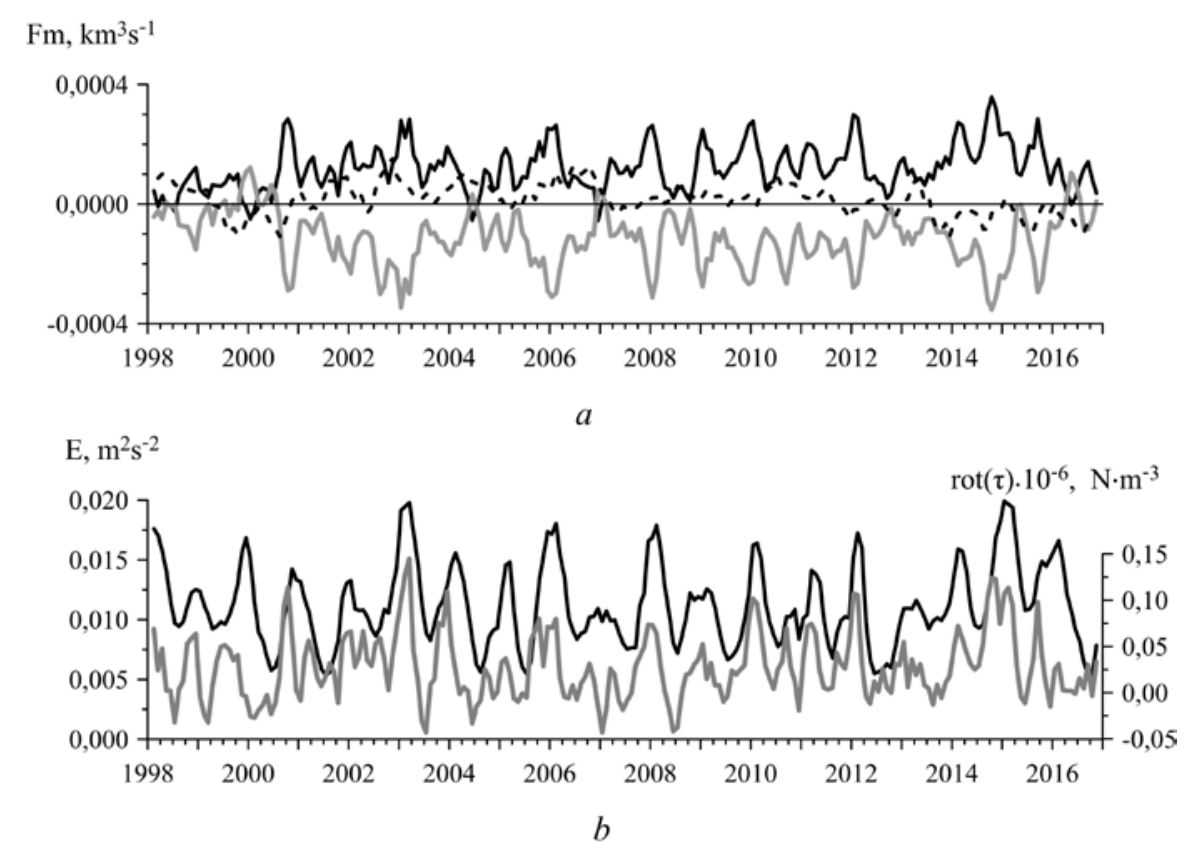

F i g. 1. Fluxes of water mass from the northwestern shelf through three surfaces: zonal section by the Cape Kaliakra (black solid line), along the $200 \mathrm{~m}$ isobath (grey line) and zonal section by the Cape Chersonesus (dotted line) (a); density of the currents' kinetic energy in the upper $50 \mathrm{~m}$ layer in the western deep-sea part of the basin (black line), average value of the wind stress vorticity for the same water area (grey line) $(b)$

The water flux through the zonal section at the Cape Kaliakra is almost always directed from the NWS (positive values of the flux on the graph), while the liquid mass flux through the surface formed by the $200 \mathrm{~m}$ isobath (lateral section) is directed mainly to the shelf. A good correlation between the maximums of the first flux and the minimums of the second one takes place. The average values of mass fluxes for the entire considered period through each of the three sections are equal to $1.2 \cdot 10^{-4}-1.16 \cdot 10^{-4}$ and $1.5 \cdot 10^{-5} \mathrm{~km}^{3} \mathrm{~s}^{-1}$ for the Cape Kaliakra, lateral surface and the Cape Chersonesus, respectively. The value of the average flux through the section at the Cape Chersonesus is an order of magnitude less than through the other two sections. The fluxes through the lateral section and the zonal section 
at the Cape Kaliakra approximately compensate each other. Water from the deepwater part of the basin enters the NWS through the lateral surface and leaves the shelf in the area of Cape Kaliakra.

The main element of circulation in the Black Sea upper layer is the intense RIM Current, localized in the continental slope area, which can weaken, meander, break into separate gyres and filaments. As shown in a number of works (for example, [10]), the Rim Current intensity is directly related to the vorticity of the wind field over the Black Sea. In Fig. $1, b$ a graph of the time dependence of the area-averaged value of the wind stress eddy, as well as the density of the kinetic energy of currents averaged over $50 \mathrm{~m}$ depth in the upper sea layer for the western deep-water part of the basin, is shown. It should be noted that the same fields were used to calculate the wind stress vortex as in the reanalysis. The kinetic energy density of the currents was obtained from the results of the reanalysis. As can be seen in this figure, the maxima of the kinetic energy density of the currents and the wind field vorticity correlate well. If we compare the graphs of the behavior of the kinetic energy density of currents and mass fluxes, we can see that high energy values correspond to the cases when maxima are observed in the mass fluxes through the section near the Cape Kaliakra and, accordingly, minima of fluxes through the lateral section. Thus, the high values of water mass fluxes on the NWS through the lateral section, as well as from the shelf through the section near the Cape Kaliakra, coincide with the Rim Current intensification, which is caused by high values of the wind field vorticity.

In Fig. 2 the examples of mean for the season currents in the upper 50-meter layer of the western part of the Black Sea at high and low values of the kinetic energy density are given.

At high values of the kinetic energy density of currents in the deep-water part of the Black Sea, a clearly pronounced RIM Current jet, which in the NWS eastern edge region partially enters the shelf (Fig. 2, a), is observed. In this case, the liquid mass flux through the surface bounded by $200 \mathrm{~m}$ isobath is directed from the deepwater part of the sea to the shelf and has maximum absolute values, while the liquid mass flux through the zonal section near Cape Kaliakra, on the contrary, is directed from the shelf and also has the maximum values (Fig. 1, a). It is important to note that the currents on the shelf itself in this case are directed to the south, which leads to the formation of a liquid flux directed from the NWS through the section near the Cape Kaliakra. Thus, the inflow of water through the eastern edge of the shelf due to the RIM Current jet is compensated by the water flux from the shelf zone to the south.

In examples with low values of the kinetic energy density (and, accordingly, low water fluxes from the shelf near Cape Kaliakra), the RIM Current jet manifests itself only fragmentarily (Fig. 2, b) or moves away from the shelf edge. It should be emphasized that in the latter case the flux center is displaced southward of the NWS and its effect on the water exchange with the shelf is small. At the same time, the nature of the currents in the upper layer of the sea manifests itself as disordered due to the large influence of eddy structures on the fluxes of the liquid mass. A distinctive feature of currents on the NWS itself (in cases of the kinetic energy density low values) is their direction along the coast to the north with the lowest absolute values of water mass fluxes across the boundaries of the NWS. 

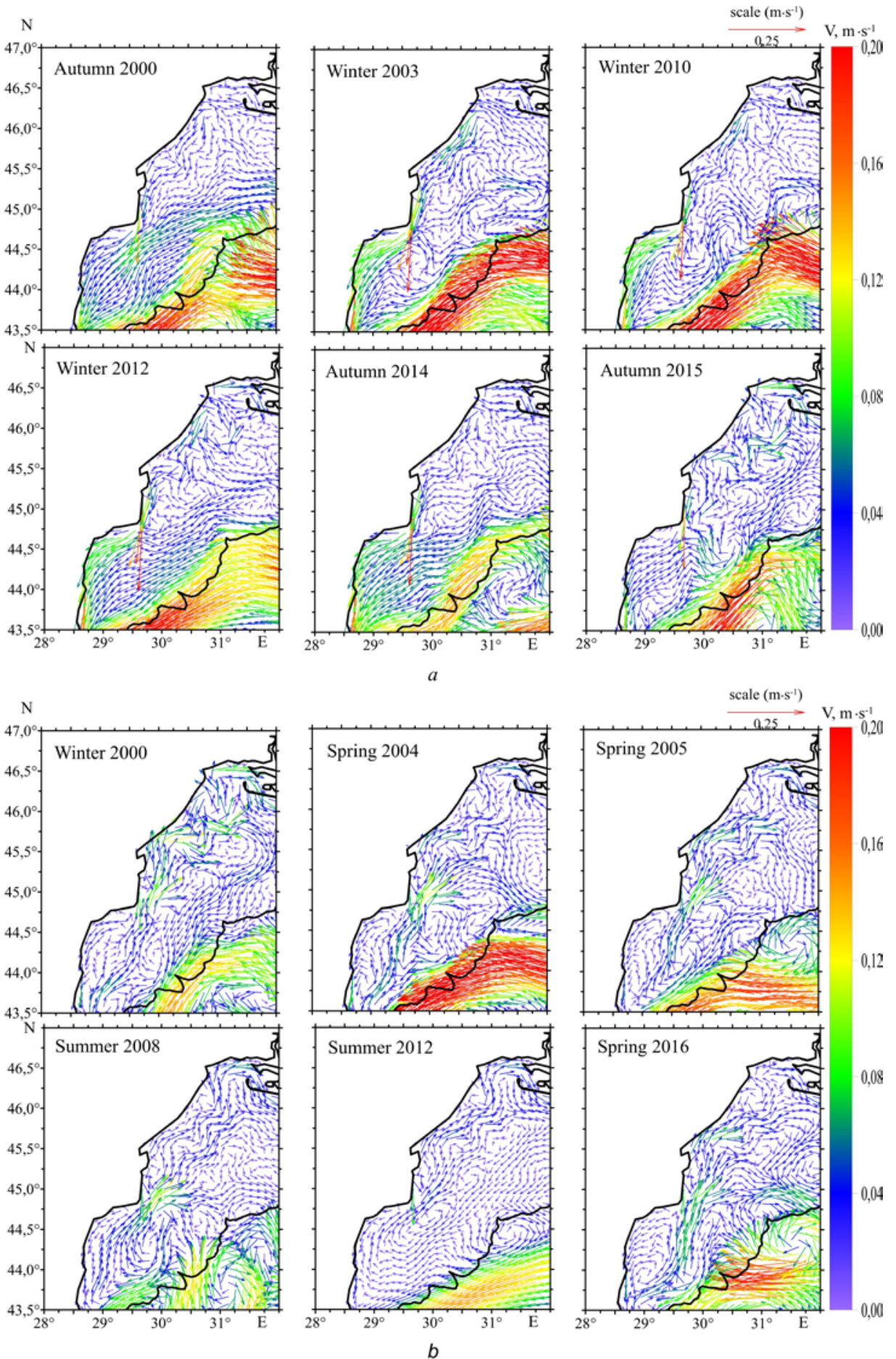

F i g. 2. Fragments of the maps of the season-average currents in the upper $50 \mathrm{~m}$ layer: $a$ - cases with high values of kinetic energy density for the western deep-sea part of the basin, $b$ - cases with low values 
The direction and magnitude of the fluxes of nutrients and ecosystem components from the shelf zone to the Black Sea deep-water part depend primarily on the direction and magnitude of the water mass fluxes carrying the impurity. The difference in impurity concentrations on the shelf and in the deep-water part also has a significant effect on the magnitude of these fluxes. As shown above, the concentration of nutrients in the surface layer of the Black Sea at the NWS, supplied mainly with river flows, is significantly higher than in the deep-water part of the sea. Satellite maps of the distribution of chlorophyll $a$ concentration show an increased content of bioproduction in shelf waters. Due to the high concentration of nutrients in the NWS, their flux into the deep-water part is generally positive. In Fig. 3 the fluxes of inorganic nitrogen (the main biogenic element in the Black Sea) and phytoplankton (one of the marine ecosystem components) through zonal sections near the Cape Kaliakra and the the Cape Chersonesus, as well as along the shelf boundary along the $200 \mathrm{~m}$ isobaths, are shown.
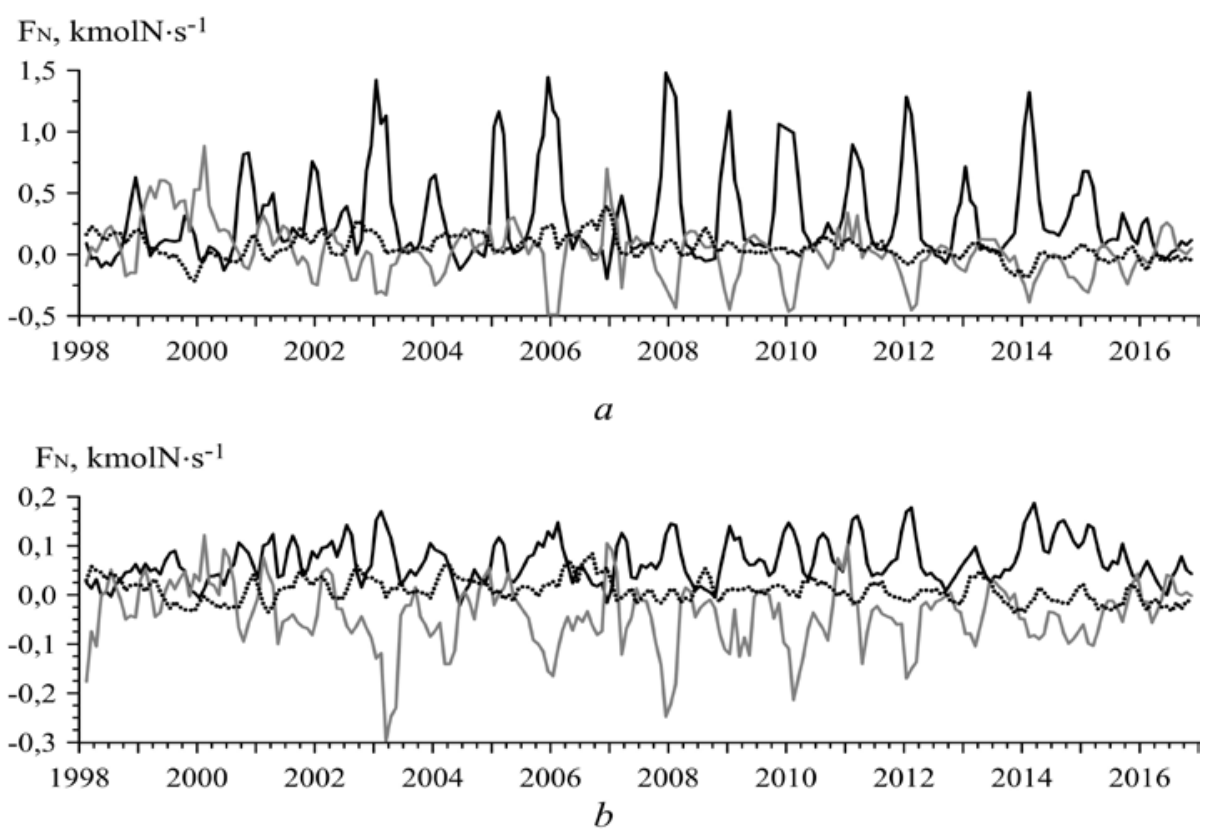

F i g. 3. Innorganic nitrogen fluxes from the northwestern shelf through three sections $(a)$ and phytoplankton fluxes (b) (line indication is the same as in Fig. 1, $a$ )

The flow of inorganic nitrogen flux (Fig. 3, a) in the Cape Kaliakra area is almost always positive and its maxima in time coincide with the maxima of the mass flux through this section. At the same time, the maxima of the nutrient flux are more pronounced than the maxima of the liquid flux due to high concentration of inorganic nitrogen compounds in the NWS waters. The nitrogen flux through the surface along $200 \mathrm{~m}$ isobath has both positive and negative values, in contrast to the liquid mass flux of liquid through this surface, which has mostly 
negative values. The maximum values of nitrogen fluxes directed from the deepwater part to the shelf (negative values on the graph) correlate with the maxima of fluxes through the zonal section at Cape Kaliakra. The nitrogen flux through the section near the Cape Chersonesus is significantly less than the flux through the other two boundaries of the shelf. At the same time, the nitrogen flux through the section near the Cape Chersonesus is almost always positive, and its average value for the entire period under consideration $\left(0.056 \mathrm{kmolN} \cdot \mathrm{s}^{-1}\right)$ is greater than through the surface along $200 \mathrm{~m}$ isobath $\left(0.018 \mathrm{kmolN} \cdot \mathrm{s}^{-1}\right)$. The largest average flux of inorganic nitrogen from the shelf falls on the zonal section near the Cape Kaliakra $-0.314 \mathrm{kmolN} \cdot \mathrm{s}^{-1}$. In contrast to the liquid mass flux, the inorganic nitrogen fluxes through all three surfaces are on average positive, and their total flux $\left(0.39 \mathrm{kmolN} \cdot \mathrm{s}^{-1}\right)$ is $\sim 25 \%$ of the amount that get to the NWS with river runoffs.

The graphs of temporal evolution of phytoplankton fluxes (Fig. 3, b) and inorganic nitrogen are qualitatively similar. The difference is that the maxima of phytoplankton fluxes through the section at the Cape Kaliakra are less than the maxima of inorganic nitrogen fluxes and more than the ones through the lateral section. On the whole, this behavior agrees well with how the fluxes of the liquid mass vary with time: the maxima of fluxes through the section near the Cape Kaliakra are observed mainly in winter and correlate well with the minima of fluxes through the lateral section. At the same time, the values of the maxima of inorganic nitrogen flux near the Cape Kaliakra noticeably exceed the values of the minima of this flux through the lateral section in absolute value, which can be explained as follows: the concentration of inorganic nitrogen on the shelf, caused by the outflow of rivers, is always higher than in the deep-water part of the sea. As for phytoplankton, during winter bloom its concentration in the deep-water part of the sea is high, and in some cases it can exceed the values on the shelf near its boundary. As a consequence, the amount of phytoplankton flux to the shelf through the lateral surface sometimes exceeds the flux directed from the shelf near the Cape Kaliakra.

The abovementioned differences in the fluxes of nutrients from the NWS to the deep-water part of the sea determine the nature of their spatial distribution. In Fig. 4 the examples of monthly average maps of inorganic nitrogen and phytoplankton distribution in the Black Sea surface layer for the type of circulation in which there is an intense RIM Current entering the NWS (see Fig. 2, a), are given. A powerful RIM Current jet along the NWS continental slope prevents the transfer of impurities across the isobaths. At the same time, the surface currents on the shelf are directed mainly to the west, as shown by the current maps. In order to compensate for this flux, an intense southward current near the western coast is formed. This current carries the most concentrated part of nutrients and bioproducts to the southern boundary of the NWS, where the RIM Current flow picks up and carries water with a high concentration of nutrients up to the Anatolian coast. The presented maps of the distribution of inorganic nitrogen and phytoplankton surface concentration demonstrate narrow bands of increased concentration, stretched rather far along the western and southern coasts. The waters with the maximum concentration of nutrients and phytoplankton in the NWS are pressed against the western coast. 

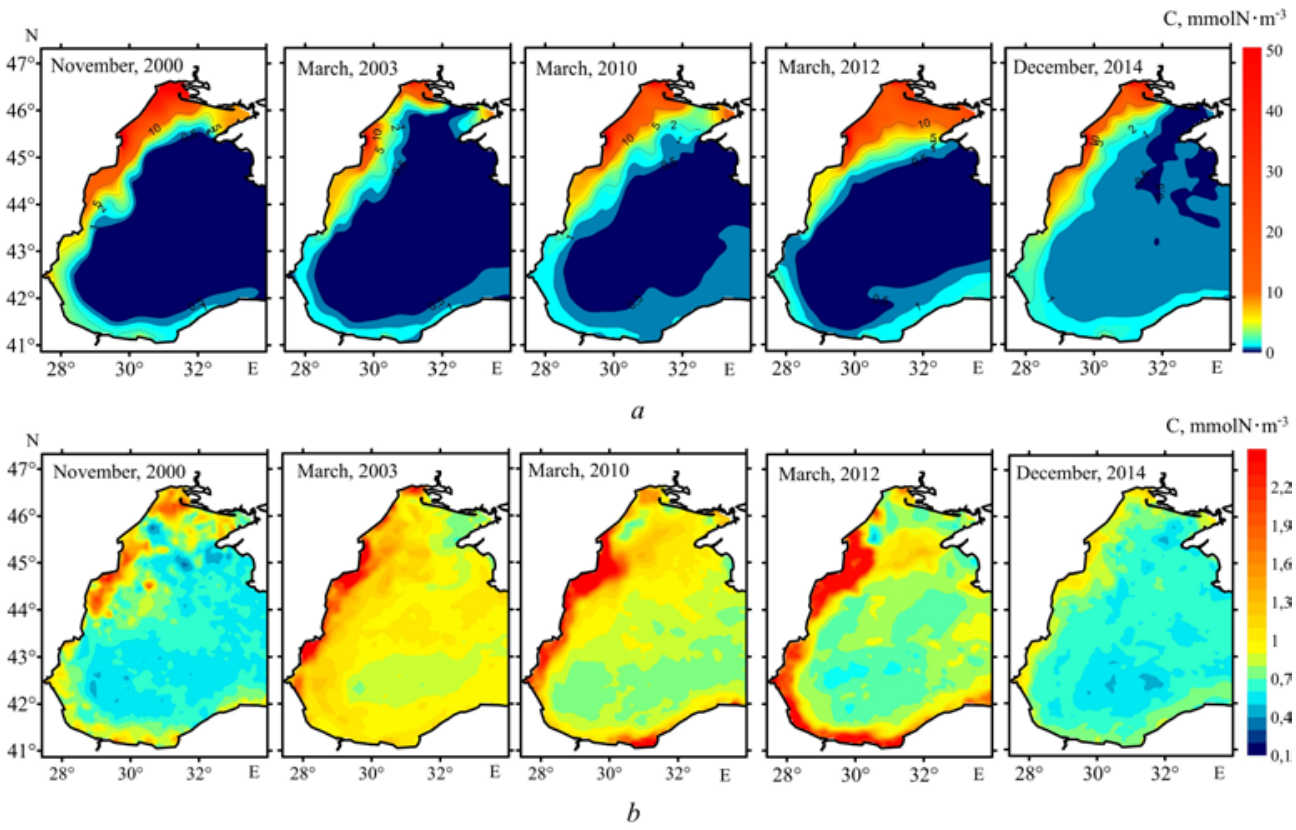

F i g. 4. Fragments of the maps of the monthly-average distribution of the inorganic nitrogen $(a)$ and phytoplankton $(b)$ surface concentrations (circulation is of the same type as in Fig. 2, $a$ )

The scheme of nutrient distribution from the NWS described above is not always observed with the NWS. In Fig. 5 the examples of the surface distribution of inorganic nitrogen and phytoplankton, which qualitatively differ from that considered earlier. A characteristic feature of circulation in these cases (see Fig. 2, b) is the absence of a clearly pronounced RIM Current jet, with the exception of the spring of 2004 and 2005, when the RIM Current is observed but its core in the northwestern part passes rather far from the shelf edge. The currents in the NWS are directed to the north and do not transfer the impurity to the deep-water part of the basin. This is an important feature of circulation for all cases shown in Fig. 2, $b$. As a consequence, the increased concentration of nutrients and bioproduction (Fig. 5) is concentrated in a relatively small area at river mouths.

Thus, the nature of circulation in the Black Sea upper layer, in particular, the intensity and position of the RIM Current jet, makes the main contribution to the distribution of ecosystem components and exchange between the shelf and the deep-water part of the basin. In this case, currents are important not only in the deep-water part of the sea, but also on the shelf. The cases when nutrients and bioproducts spread far along the coast correspond to circulation with a pronounced RIM Current jet pressed against the shelf edge and the western coast of the Black Sea. With this type of circulation on the NWS, the surface currents directed to the west are formed. As a result of this fact an alongshore current develops, transporting the admixture to the south, where it is picked up by the RIM Current jet. An increased concentration of ecosystem components is observed only on the shelf in the case when the RIM Current jet moves away from the shelf edge, or appears fragmentarily. In this case, the liquid mass flux through the surface along the $200 \mathrm{~m}$ isobath is directed mainly from the NWS. For compensating this flux, 
a northward current appears on the shelf (see Fig. 2, b), blocking the impurity and preventing it from spreading along the western and then southern shores of the Black Sea.
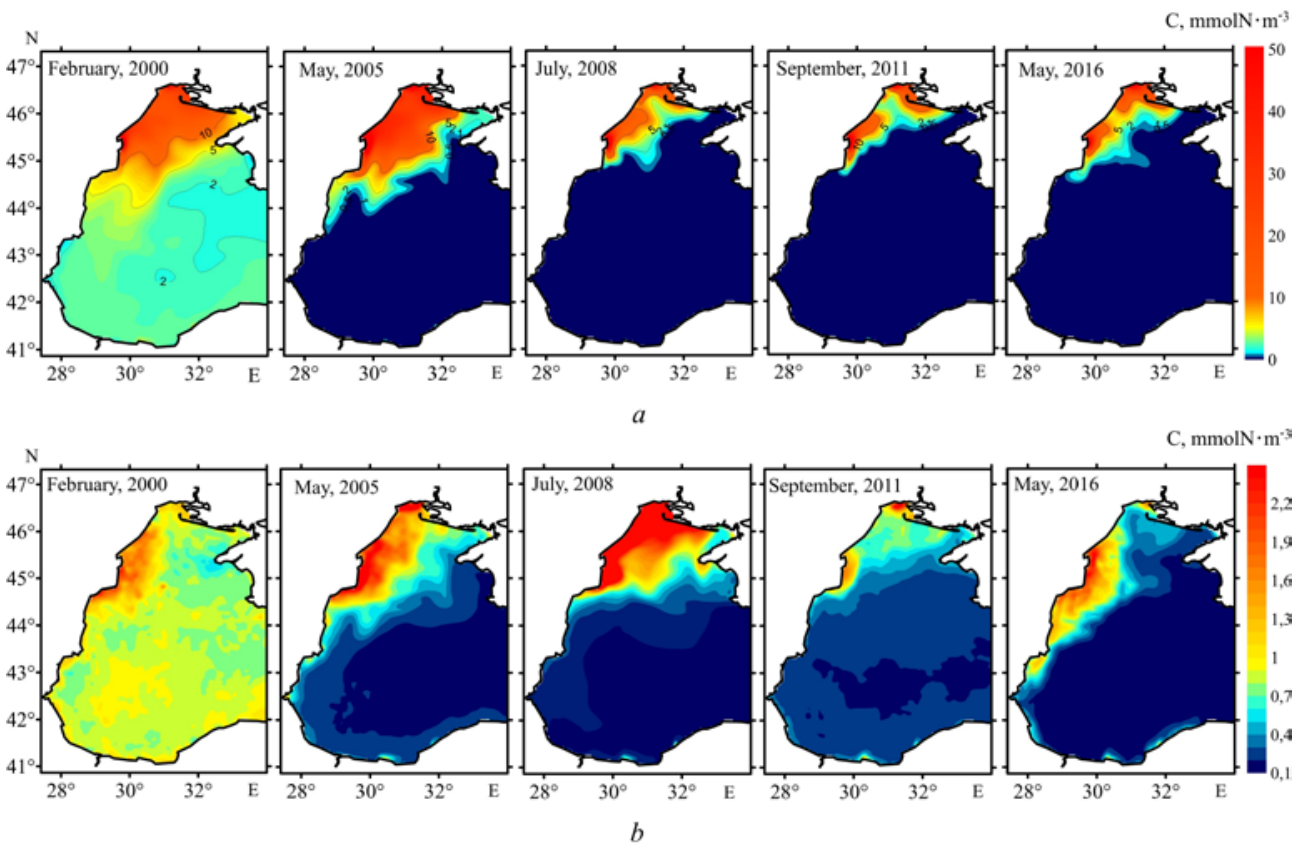

F i g. 5. Fragments of the maps of the monthly-average distribution of the inorganic nitrogen $(a)$ and phytoplankton (b) surface concentrations (for the circulation type as in Fig. 2, $b$ )

\section{Conclusion}

The paper analyzes the features of the ecosystem components transfer from the NWS to the Black Sea deep-water part. The fluxes of nutrients and bioproducts were calculated using the Black Sea hydrophysical and biogeochemical fields on a regular grid. These fields were obtained as a result of a reanalysis carried out on the basis of the Black Sea ecosystem model with the assimilation of remote sensing data both in the numerical circulation model and in the biogeochemical block.

Since the direction and magnitude of nutrient and bioproduction fluxes are mainly determined by the circulation in the upper sea layer, the water mass fluxes were also calculated. The greatest value of the liquid mass flux from the shelf is observed through the zonal section at the southern boundary of the NWS (the Cape Kaliakra), and the smallest - through the section near the Cape Chersonesus. The mass flux through the surface along the $200 \mathrm{~m}$ isobath is on average directed to the NWS and compensates for the mass flux near the Cape Kaliakra. This character of fluxes is mainly determined by the location of the RIM Current jet. When it is pressed against the edge of the NWS, it partially enters the shelf, as a result of which the mass flux is directed towards the shelf. To compensate for the influx of liquid, a southward current appears on the shelf, as a result of which water flows out of the shelf near the Cape Kaliakra. When the RIM Current jet is weak or passes far from the shelf edge, the water flux across the surface along the $200 \mathrm{~m}$ isobath is close to zero or even directed from the shelf into the deep sea. 
In this case, a northward current is formed on the shelf, the flux near the Cape Kaliakra has minimal values and occasionally it is directed toward the shelf. The analysis showed that the behavior of the RIM Current jet, and, consequently, the direction and magnitude of fluxes through the NWS boundaries depend on the wind stress vorticity over the western part of the Black Sea. The higher the value of the wind field vorticity (the maximum values are observed mainly in the winter season), the more intense the RIM Current jet and, accordingly, the higher the values of fluxes through the surface along the $200 \mathrm{~m}$ isobath (towards the shelf) and through the zonal section near the Cape Kaliakra (from the shelf ).

The nature of nutrients and bioproduction distribution from the NWS is also determined to a large extent by the direction and magnitude of the fluxes of the liquid mass. The fluxes of inorganic nitrogen and phytoplankton are qualitatively consistent with the fluxes of the liquid mass. The difference in the concentration of this impurity in the shelf zone and in the deep-water part of the Black Sea has a significant effect on the magnitude of the impurity fluxes. Since the concentration of inorganic nitrogen on the shelf is, as a rule, higher than in the deep-water part of the sea due to the river outflow, the maxima of fluxes through the section near the Cape Kaliakra increase and the minima of fluxes through the lateral section decrease. For phytoplankton fluxes, the opposite picture can be traced, which can be explained by the fact that in the winter season (when mainly the maxima of these fluxes are observed) the phytoplankton concentration in the deep-water part of the sea is high due to the supply of nutrients to the surface layer from deeper layers.

The nature of circulation in the upper layer also affects the distribution pattern of the phytoplankton and inorganic nitrogen surface concentration. The circulation with an intense jet of the RIM Current, pressed against the shelf edge, corresponds to the distribution pattern of surface concentration in the form of a narrow strip of high values along the western and partly southern coasts of the Black Sea. When the RIM Current jet is weak or moves away from the shelf edge, which is observed at low values of the wind field vorticity, the increased concentration values are concentrated at the NWS.

\section{REFERENCES}

1. Tolmazin, D., 1985. Changing Coastal Oceanography of the Black Sea. I: Northwestern Shelf. Progress in Oceanography, 15(4), pp. 217-276. https://doi.org/10.1016/0079-6611(85)90038-2

2. Beckers, J.M., Gregoire, M., Nihoul, J.C.J., Stanev, E., Staneva, J. and Lancelot, C., 2002. Modelling the Danube-Influenced North-Western Continental Shelf of the Black Sea. I: Hydrodynamical Processes Simulated by 3-D and Box Models. Estuarine, Coastal and Shelf Science, 54(3), pp. 453-472. doi:10.1006/ecss.2000.0658

3. Demyshev, S.G., 2011. Prognostic Numerical Analysis of Currents in the Black Sea with High Horizontal Resolution. Physical Oceanography, 21(1), 33. https://doi.org/10.1007/s11110-0119102-x

4. Oguz, T. and Velikova, V., 2010. Abrupt Transition of the Northwestern Black Sea Shelf Ecosystem from a Eutrophic to an Alternative Pristine State. Marine Ecology Progress Series, 405, pp. 231-242. doi:10.3354/meps08538

5. Lancelot, C., Staneva, J., van Eeckhout, D., Beckers, J.-M. and Stanev, E., 2002. Modelling the Danube-Influenced North-Western Continental Shelf of the Black Sea. II: Ecosystem Response to Changes in Nutrient Delivery by the Danube River after Its Damming in 1972. Estuarine, Coastal and Shelf Science, 54(3), pp. 473-499. doi:10.1006/ecss.2000.0659 
6. Grégoire, M., Soetaert, K., Nezlin, N. and Kostianoy, A., 2004. Modeling the Nitrogen Cycling and Plankton Productivity in the Black Sea Using a Three-Dimensional Interdisciplinary Model. Journal of Geophysical Research: Oceans, 109(C5), C05007. doi:10.1029/2001JC001014

7. Stanev, E., Beckers, J.M., Lancelot, C., Staneva, J.V., Le Traon, P.Y., Peneva, E.L. and Gregoire, M., 2002. Coastal-Open Ocean Exchange in the Black Sea: Observations and Modelling. Estuarine, Coastal and Shelf Science, 54(3), pp. 601-620. doi:10.1006/ecss.2000.0668

8. Shapiro, G.I., Stanichny, S.V., Stanychna, R.R., 2010. Anatomy of Shelf-Deep Sea Exchanges by a Mesoscale Eddy in the North West Black Sea as Derived from Remotely Sensed Data. Remote Sensing of Environment, 114(4), pp. 867-875. https://doi.org/10.1016/j.rse.2009.11.020

9. Kubryakov, A.A., Stanichny, S.V. and Zatsepin, A.G., 2018. Interannual Variability of Danube Waters Propagation in Summer Period of 1992-2015 and Its Influence on the Black Sea Ecosystem. Journal of Marine Systems, 179, pp. 10-30. https://doi.org/10.1016/j.jmarsys.2017.11.001

10. Dorofeev, V.L. and Sukhikh, L.I., 2016. Analysis of Variability of the Black Sea Hydrophysical Fields in 1993-2012 Based on the Reanalysis Results. Physical Oceanography, (1), pp. 33-47. doi:10.22449/1573-160X-2016-1-33-47

11. Dorofeyev, V.L. and Sukhikh, L.I., 2017. Some Trends in the Long-Term Variability of the Black sea Hydrophysical Fields on the Results of the Reanalysis. In: MHI, 2017. Ecological Safety of Coastal and Shelf Zones of Sea. Sevastopol: ECOSI-Gidrofizika. Iss. 1, pp. 15-22 (in Russian).

12. Korotaev, G.K., Oguz, T., Dorofeyev, V.L., Demyshev, S.G., Kubryakov, A.I. and Ratner, Yu.B., 2011. Development of Black Sea Nowcasting and Forecasting System. Ocean Science, 7(5), pp. 629-649. https://doi.org/10.5194/os-7-629-2011

13. Dee, D.P., Uppala, S.M., Simmons, A.J., Berrisford, P., Poli, P., Kobayashi, S., Andrae, U., Balmaseda, M.A. and Balsamo, G. [et al.], 2011. The ERA-Interim Reanalysis: Configuration and Performance of the Data Assimilation System. Quarterly Journal of the Royal Meteorological Society, 137(656), pp. 553-597. doi:10.1002/qj.828

14. Ludwig, W., Dumont, E., Meybeck, M. and Heussner, S., 2009. River Discharges of Water and Nutrients to the Mediterranean and Black Sea: Major Drivers for Ecosystem Changes During Past and Future Decades? Progress in Oceanography, 80(3-4), pp. 199-217. https://doi.org/10.1016/j.pocean.2009.02.001

15. Suslin, V. and Churilova, T., 2016. A Regional Algorithm for Separating Light Absorption by Chlorophyll-a and Coloured Detrital Matter in the Black Sea, Using 480-560 nm Bands from Ocean Colour Scanners. International Journal of Remote Sensing, 37(18), pp. 4380-4400. doi:10.1080/01431161.2016.1211350

16. Dorofeyev, V. and Sukhikh, L., 2018. A Model for Monitoring the Evolution of the Black Sea Ecosystem on the Basis of Remote Sensing Data Assimilation. International Journal of Remote Sensing, 39(24), pp. 9339-9355. doi:10.1080/01431161.2018.1523589

About the authors:

Victor L. Dorofeyev - Senior Research Associate, Marine Hydrophysical Institute of RAS (2 Kapitanskaya St., Sevastopol, 299011, Russian Federation), Ph. D. (Phys.-Math.), ResearcherID: G-1050-2014, viktor.dorofeev@mhi-ras.ru

Larisa I. Sukhikh - Junior Research Associate, Marine Hydrophysical Institute of RAS (2 Kapitanskaya St., Sevastopol, 299011, Russian Federation), ResearcherID: M-4381-2018, l.sukhikh@gmail.com

Contribution of the co-authors:

Victor L. Dorofeyev - statement of the problem, carrying out the numerical calculations, analysis of the obtained results

Larisa I. Sukhikh - carrying out the numerical calculations, analysis of the obtained results

All the authors have read and approved the final manuscript.

The authors declare that they have no conflict of interest. 